\title{
HAG regimen improves survival in adult patients with hypocellular acute myeloid leukemia
}

\author{
Xiaoxia $\mathrm{Hu}^{1,{ }^{*}}$, Weijun Fu ${ }^{2,}{ }^{*}$, Libing Wang ${ }^{1}$, Lei Gao ${ }^{1}$, Shuqin Lü ${ }^{1}$, Hao Xí ${ }^{2}$, Huiying \\ Qiu $^{1}$, Li Chen ${ }^{1}$, Jie Chen ${ }^{1}$, Xiong $\mathrm{Ni}^{1}$, Xiaoqian $\mathrm{Xu}^{1}{ }^{1}$, Weiping Zhang ${ }^{1}$, Jianmin Yang ${ }^{1}$, \\ Jianmin Wang ${ }^{1}$ and Xianmin Song ${ }^{1}$ \\ ${ }^{1}$ Department of Hematology, Institute of Hematology, Changhai Hospital, Second Military Medical University, Shanghai, \\ China \\ 2 Department of Hematology, Changzheng Hospital, Second Military Medical University, Shanghai, China \\ * These authors have contributed equally to this paper \\ Correspondence to: Xianmin Song, email: shongxm@139.com
}

Jianmin Wang, email: jmwang@medmail.com.cn

Keywords: hypocellular, acute myeloid leukemia, induction regimen, prognosis

Received: June 02, $2015 \quad$ Accepted: October 08, $2015 \quad$ Published: October 21, 2015

This is an open-access article distributed under the terms of the Creative Commons Attribution License, which permits unrestricted use, distribution, and reproduction in any medium, provided the original author and source are credited.

\section{ABSTRACT}

\section{Background:}

Hypocellular acute myeloid leukemia (Hypo-AML) is a rare disease entity. Studies investigating the biological characteristics of hypo-AML have been largely lacking. We examined the clinical and biological characteristics, as well as treatment outcomes of hypo-AML in our institutes over a seven years period.

Design and Methods:

We retrospectively analyzed data on 631 adult AML patients diagnosed according to the French-American-British (FAB) classification and WHO classification of tumors of haematopoietic and lymphoid tissue, including 43 patients with hypo-AML. Biological variables, treatment outcomes and follow-up data on hypo-AML patients were analyzed.

Results:

Out of $631 \mathrm{AML}$ patients, $47(7.4 \%)$ were diagnosed as hypo-AML, out of which 43 patients were evaluable. Compared with non-hypocellular AML, hypo-AML patients tended to be older $(P=0.05)$, more likely to present with leukocytopenia $(P<0.01)$ and anterior hematological diseases $(P=0.02)$. The overall complete remission $(C R)$ rate, disease free survival (DFS), and overall survival (OS) in hypo-AML patients were comparable to those in non-hypo AML patients. Twenty-seven (62.8\%) patients with hypocellular AML were treated with the standard regimen of anthracyclines and cytarabine (XA) (associated CR rate: 51.9\%; median OS: 7 months; median DFS: 6.5 months). Sixteen (37.2\%) patients were treated with a priming regimen containing homoharringtonine, cytarabine and G-CSF (HAG) (associated CR rate: 81.25\%; median OS: 16 months; median DFS: 16 months).

Conclusions:

The overall prognosis of hypo-AML was not inferior to that of non-hypo AML. HAG regimen might increase response rates and improve survival in hypo-AML patients.

\section{INTRODUCTION}

While most cases of acute myeloid leukemia (AML) are hypercellular or normocellular, up to $5-12 \%$ of all cases are that of hypocellular AML (Hypo-AML).[1-5] The clinical course, diagnosis and management of nine cases of hypoplastic acute myelogeneous leukemia was 
Table 1: Patient characteristics by study group

\begin{tabular}{|c|c|c|c|}
\hline & Нуро-AML & Non-hypo-AML & $P$ \\
\hline Total patients $(\mathrm{N})$ & 43 & 541 & \\
\hline Female sex, N (\%) & $21(48.8)$ & $229(42.3)$ & 0.42 \\
\hline Median age, y (range) & $56(20-65)$ & $46(15-78)$ & 0.05 \\
\hline AHD, No. $(\%)$ & $10(23.2)$ & $43(8)$ & 0.02 \\
\hline Median WBC count, $\times 10^{9} / \mathrm{L}$ (range) & $2.2(0.2-64.4)$ & $12.6(0.5-247)$ & $<0.01$ \\
\hline $\begin{array}{l}\text { Median HGB level, } \\
\text { g/L (range) }\end{array}$ & $83(30-142)$ & $82(35-134)$ & 0.8 \\
\hline Median platelet count, $\times 10^{9} / \mathrm{L}$ (range) & $51(4-306)$ & $35(1-374)$ & 0.42 \\
\hline $\begin{array}{l}\text { Median bone marrow cellularity, } \\
\% \text { (range })\end{array}$ & $14(11-20)$ & $56(24-82)$ & 0.03 \\
\hline Median blasts in bone marrow $(\%)$ & $43(24-85)$ & $53(20-96)$ & 0.53 \\
\hline $\begin{array}{l}\text { Cytogenetics, No. (\%) } \\
\text { Poor } \\
\text { Intermediate } \\
\text { Favorable }\end{array}$ & $\begin{array}{l}19(44.2) \\
19(44.2) \\
5(11.6)\end{array}$ & $\begin{array}{l}209(38.6 \%) \\
275(50.8 \%) \\
57(10.5 \%)\end{array}$ & $\begin{array}{l}0.72 \\
0.81 \\
0.24\end{array}$ \\
\hline CR, No. $(\%)$ & $27(62.8 \%)$ & $303(56.0 \%)$ & 0.48 \\
\hline Median OS, months & 9 & 8 & 0.7 \\
\hline Median DFS, months & 8 & 10 & 0.9 \\
\hline
\end{tabular}

Hypo-AML, Hypocellular acute myeloid leukemia; AHD, anterior hematological disease; HGB, hemoglobin; $\mathrm{CR}$, complete remission; OS, overall survival; DFS, disease free survival

first described in 1975.[3] In 1996, Nagai K et al proposed the diagnostic criteria for hypo-AML (cellularity of bone marrow $<40 \%$ and blast percentage $>30 \%$ in absolute nucleated cells (ANC).[6] Currently, hypo-AML is defined as bone marrow cellularity $<20 \%$ on biopsy, although in some earlier reports, cellularity less than $40 \%$ to $50 \%$ has been considered as indicating hypo-AML.[2, 4, 7, 8]

The treatment options for hypo-AML [9, 10], complete remission (CR) rates, overall survival (OS), duration of remission, and event-free survival (EFS) were found to be comparable to those of patients with non-hypocellular AML in a large study on 123 patients of hypo-AML and 1219 non-hypocellular AML. In this study, incidence of early death during the first four weeks was relatively high, which markedly influenced the OS. [9] So the optimal induction chemotherapy regimen remains undefined.

Because of its low incidence, the documented clinical experience with this type of adult leukemia is limited. We undertook this study to assess the frequency of hypo-AML among a large Chinese cohort of patients with AML. We describe the clinical features of this group and compare their clinical outcomes with those of other patients with AML, to assess the impact of this pathologic feature on prognosis, and to evaluate the efficacy of different induction regimens.

\section{RESULTS}

\section{Clinical and biological characteristics}

There were 631 patients with de novo AML seen at the department of Hematology, Changhai and Changzheng hospital during the study period. 47 patients (7.4\%) were diagnosed as hypo-AML (bone marrow cellularity $<20 \%$ ) based on bone marrow biopsy. One patient did not opt for therapy due to poor general condition. The other 3 patients were excluded due to lack of availability of complete data. 43 patients were evaluable for the study. The clinical features of patients with hypo-AML are summarized in 
Table 2: Patient's distribution by FAB classification and mutation analysis

\begin{tabular}{|l|l|l|l|}
\hline & $\mathbf{N}$ & \% & Total \\
\hline FAB classification & & & 43 \\
\hline M1 & 7 & 16.3 & \\
\hline M2 & 14 & 32.5 & \\
\hline M5 & 22 & 51.2 & \\
\hline Mutation analysis & & & $\begin{array}{l}\text { Analyzed (N, \% of total) } \\
(37,86 \%)\end{array}$ \\
\hline NPM1 & 3 & 8.1 & \\
\hline FLT3-ITD & 2 & 5.4 & \\
\hline
\end{tabular}

FAB, French-American-British; NPM1, nucleophosmin; FLT3-ITD, FMS-Like Receptor Tyrosine Kinase-3 Internal Tandem Duplication

Table 1. Of the remaining 584 non-hypocellular AML patients, 541 patients were evaluable.

In this study, 22 males and 21 females were diagnosed with hypo-AML. Median age was 56 years (range: 20-65 years) and the median bone marrow cellularity was $14 \%$ (range: $11-20 \%$ ). According to the French-American-British (FAB) classification, M2 (14/43, $32.5 \%)$, M5 (22/43, 51.2\%), and M1 (7/43, 16.3\%) were the most frequent subtypes (Table 2). The median white blood cell (WBC) count, hemoglobin (HB), platelets (PLT) were 2.2 (range: $0.2-64.4$ ) $\times 10^{9} / \mathrm{L}, 83$ (range: 30 142) $\mathrm{g} / \mathrm{L}$, and 51 (range: 4-306) $\times 10^{9} / \mathrm{L}$, respectively. Four patients had a WBC count greater than $10.0 \times 10^{9} / \mathrm{L}$, and three of them had prior myeloproliferative neoplasm (MPN) but with evidence of fibrosis on biopsy. The median percentage of blasts in bone marrow was $43 \%$ (range: $24-85 \%$ ). Ten patients had anterior hematological disease (AHD, 4 patients with MPN, and 6 patients with myelodysplastic syndrome [MDS]).

In 21 patients, valid chromosome profiles were obtained during the therapy. The cytopreserved cells of the remaining 22 patients without cytogenetic information at diagnosis were retrieved and analyzed retrospectively. Five patients had $\mathrm{t}(8 ; 21)(\mathrm{q} 22 ; \mathrm{q} 22)$ or inv (16) (p13.1q22) or t $(16 ; 16)$ (p13.1; q22). Six patients had complex chromosomal abnormalities. Nine patients had abnormalities in chromosome 7, two patients had $-5 \mathrm{q}$, and two patients had mixed lineage leukemia (MLL) rearrangement.

The nucleophosmin (NPM1) and FMS-Like Receptor Tyrosine Kinase-3 Internal Tandem Duplication (FLT3-ITD) mutation analysis was done in 37 (37/43, $86 \%$ ) patients; only 2 were found positive for FLT3-ITD, and 3 were positive for NPM1 mutation (Table 2).

\section{Clinical and biological characteristics of hypo- and non-hypo AML}

Several differences were observed in the clinical presentation of patients with and without hypocellular AML. Hypo-AML was more frequently associated with
AHD $(P=0.02)$, lower white blood cell counts $(P<0.01)$, and older age $(P=0.05)$. Other clinical characteristics such as hemoglobin (HB), platelet counts (PLT) and cytogenetic characteristics were comparable between the two groups. The CR rate for hypo-AML and nonhypo AML was $62.8 \%$ and $56 \%$, respectively $(P=0.48)$. Median OS time was 9 months and 8 months, respectively. ( $P=0.7$, Figure 2A) Among patients who achieved CR, the median duration of disease-free survival (DFS) was 8 months and 10 months, respectively $(P=0.9$, Figure $2 \mathrm{~B})$.

\section{Induction therapy and its predictive factors}

The results of induction therapy are shown in tables 3 and 4 . A total of 16 out of 43 patients $(37.2 \%)$ were prescribed a priming regimen containing homoharringtonine, cytarabine and G-CSF (HAG regimen), while 27 of 43 patients $(62.8 \%)$ enrolled in the standard regimen cohort containing anthracyclines and cytarabine ("XA" regimen). Six patients (6/27, 22.2\%) aged $>60$ years received XA induction, while 5 patients $(5 / 16,31.25 \%)$ were treated with HAG $(P=0.719)$. In this study, frail patients and those with AHD were found more likely to have received $\mathrm{HAG}$ induction. Eight patients $(8 / 43,18.6 \%)$ did not achieve any responses with one cycle of induction (6 in XA group and 2 in HAG group). Nineteen patients who achieved partial remission (PR) with one cycle of induction were re-induced with the same induction regimen, out of which 11 (11/19, 57.9\%) achieved CR. After 2 cycles of induction, 4 patients were found to have resistant disease. Fourteen patients achieved CR with XA regimen $(14 / 27,51.8 \%)$ and 13 patients with HAG $(13 / 16,81.25 \%) .1$ patient $(6.25 \%)$ died during induction in the HAG cohort as compared to $4(14.8 \%)$ in the XA cohort $(P=0.635)$. No significant differences were observed between the causes of death during induction among the 2 induction regimens. During induction, patients induced with $\mathrm{HAG}$ regimen experienced a mildly prolonged myelosuppression. The duration of agranulocytosis was 7.8 days and 9.4 days in XA and HAG groups $(P=0.042)$. Duration of time for which the 
Table 3: Characteristics and clinical outcomes in hypo-AML patients induced with XA or HAG regimen

\begin{tabular}{|l|l|l|l|}
\hline & XA & HAG & $P$ \\
\hline No. of patients & 27 & 16 & \\
\hline Female sex, N (\%) & $13(48.1)$ & $8(50)$ & 1 \\
\hline Median age, y (range) & $50(29-65)$ & $56.5(20-65)$ & 0.555 \\
\hline Age $\geq 60$ y (\%) & $6(22.2)$ & $5(31.25)$ & 0.719 \\
\hline AHD, N (\%) & $7(25.9)$ & $3(18.75)$ & 0.719 \\
\hline Performance status > & $2(7.4)$ & $6(37.5)$ & 0.037 \\
\hline $\begin{array}{l}\text { Cytogenetics, N (\%) } \\
\text { poor } \\
\text { intermediate } \\
\text { favorable }\end{array}$ & $\begin{array}{l}12(44.4) \\
13(48.4) \\
\text { Duration of agranulocytosis (d) }\end{array}$ & $\begin{array}{l}7(43.75) \\
6(37.5) \\
3(18.75)\end{array}$ & 0.504 \\
\hline $\begin{array}{l}\text { Duration of platelets } \\
<20 \times 10^{9} / \text { L (d) }\end{array}$ & 7.8 & 9.4 & 0.042 \\
\hline CR (\%) & 8.2 & 11.2 & 0.061 \\
\hline Allo-HSCT & $14(51.9)$ & $13(81.25)$ & 0.101 \\
\hline Median OS, months & $5(18.5)$ & $4(25)$ & 0.706 \\
\hline Median DFS, months & 7 & 16 & 0.0206 \\
\hline Treatment related mortality & 6.5 & 16 & 0.2316 \\
\hline
\end{tabular}

Hypo-AML, Hypocellular acute myeloid leukemia; XA, anthracyclines and cytarabine; HAG, homoharringtonine, cytarabine and G-CSF; AHD, anterior hematological disease; CR, complete remission; OS, overall survival; DFS, disease free survival.

Table 4: Characteristics of patients with CR versus no CR

\begin{tabular}{|l|l|l|l|}
\hline Characteristics & CR & No CR & $P$ \\
\hline No. of patients & 27 & 16 & \\
\hline Female sex, N (\%) & $15(55.6)$ & $6(37.5)$ & 0.256 \\
\hline Median age, y (range) & $54(20-65)$ & $57.5(35-65)$ & 0.061 \\
\hline AHD, N (\%) & $3(11.11)$ & $7(43.75)$ & 0.021 \\
\hline Median WBC count, $\times 10^{9} / \mathrm{L}$ (range) & $1.6(0.3-51.6)$ & $3.2(1.2-13.3)$ & 0.472 \\
\hline Median HGB level, g/L (range) & $89(40-151)$ & $76.5(48-109)$ & 0.211 \\
\hline Median platelet count, $\times 10^{9} / \mathrm{L}$ (range) & $53(9-212)$ & $50.5(6-248)$ & 0.323 \\
\hline $\begin{array}{l}\text { Cytogenetics, N }(\%) \\
\text { poor } \\
\text { intermediate } \\
\text { favorable }\end{array}$ & $\begin{array}{l}7(25.9) \\
15(55.6)\end{array}$ & $\begin{array}{l}12(75) \\
4(25)\end{array}$ & 0.003 \\
\hline $\begin{array}{l}\text { Induction treatment, N (\%) } \\
\text { XA regimen } \\
\text { HAG regimen }\end{array}$ & $5(18.5)$ & $13(81.25)$ & 0.062 \\
\hline
\end{tabular}

$\mathrm{CR}$, complete remission; AHD, anterior hematological disease; HGB, hemoglobin; XA, anthracyclines and cytarabine; HAG, homoharringtonine, cytarabine and G-CSF;

Table 5: Multivariate analysis for covariates for complete remission

\begin{tabular}{|l|l|l|}
\hline Characteristic & Odds ratio & $\boldsymbol{P}$ \\
\hline Age & $0.9088(0.8225,1.0042)$ & 0.060 \\
\hline AHD & $5.4849(0.8002,37.5967)$ & 0.083 \\
\hline Cytogenetics & $0.0684(0.0090,0.5208)$ & 0.010 \\
\hline Induction treatment regimen & $16.6404(1.4128,195.9899)$ & 0.025 \\
\hline
\end{tabular}

AHD, anterior hematological disease 
platelet count was $<20 \times 10^{9} / \mathrm{L}$ was slightly longer in the HAG group as compared to that in the XA group $(P=$ $0.061)$.

The characteristics of patients with hypo-AML with or without $\mathrm{CR}$ are shown in Table 4. On univariate analysis, AHD and poor cytogenetics appeared to be associated with induction failure. XA induction regimen was marginally associated with treatment failure $(P=$

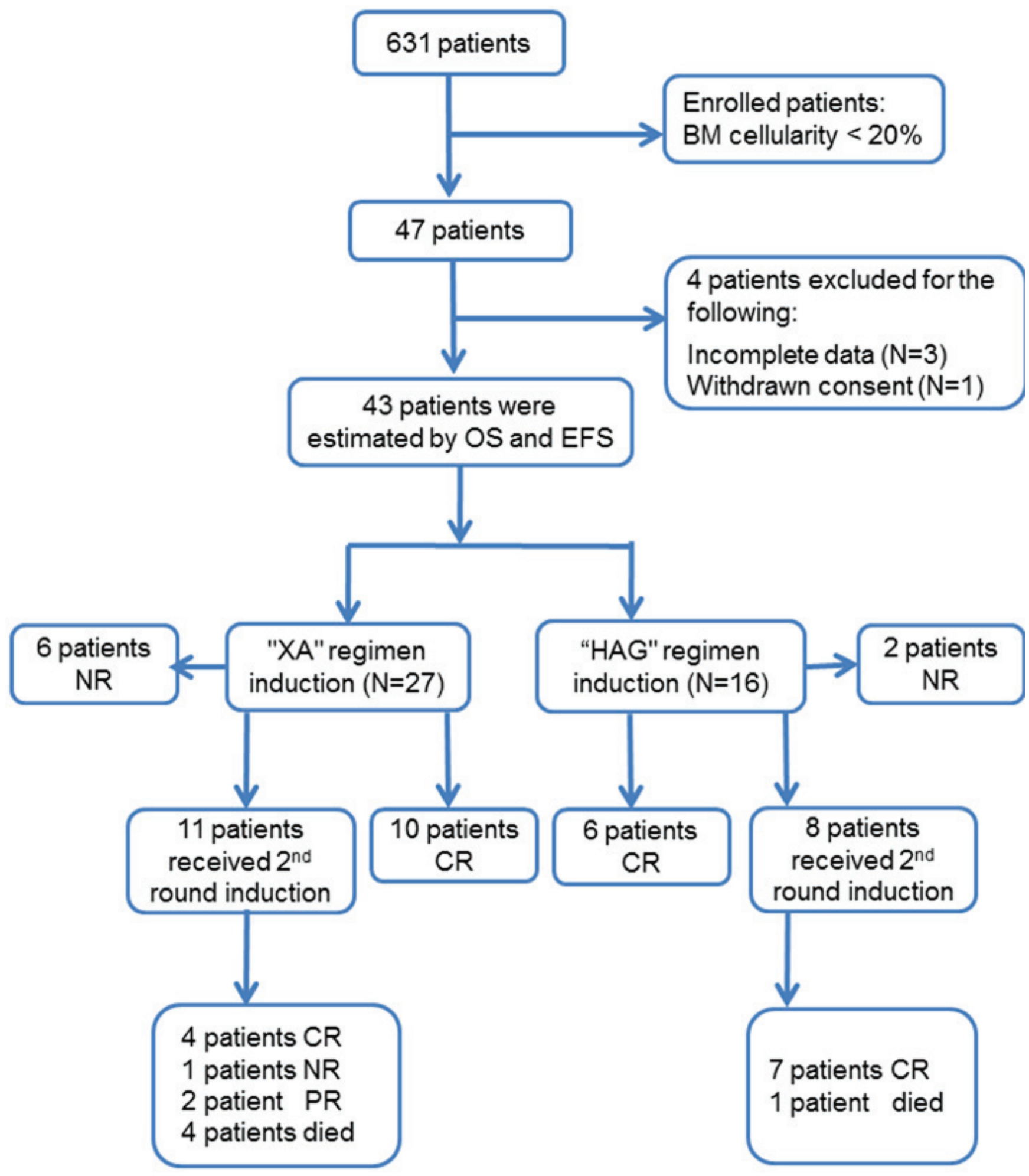

Figure 1: Study design and outcomes. 
Table 6: Summary of reports on hypocellular acute myeloid leukemia

\begin{tabular}{|c|c|c|c|c|}
\hline & Our study & Al-Kali [9] & Naseem S [10] & Nagai K [6] \\
\hline Reference time period & $2003-2013$ & $2000-2009$ & $2012-2013$ & Before 1992 \\
\hline No. of patients, hAML/all AML & $43 / 541$ & $123 / 1342$ & $8 / 316$ & 32 \\
\hline Age, y (range) & $56(20-65)$ & $65(19,88)$ & $44(16-50)$ & $67(44,75)$ \\
\hline Female, $\%$ & $21(48.8)$ & NA & $3(37.5)$ & $9(28.1)$ \\
\hline AHD, N (\%) & $10(23.3)$ & $41(33.3)$ & $4(50)$ & N.A. \\
\hline WBC count, $\times 10^{9} / \mathrm{L}$ (range) & $2.2(0.2-64.4)$ & $1.7(0.2,64.4)$ & $2.65(1.5,4)$ & $1.45(0.55,4.5)$ \\
\hline HGB level, g/L (range) & $83(30-142)$ & $87(30,142)$ & $76(48,111)$ & $81(38,132)$ \\
\hline PLT count, $\times 10^{9} / \mathrm{L}$ (range) & $51(4-306)$ & $57(4,306)$ & $42.5(5,391)$ & $52.5(1.5,262.5)$ \\
\hline BM cellularity, \% (range) & $14(11-20)$ & $15(4-20)$ & $\leq 40 \%$ & $29.8(12.4-39.8)$ \\
\hline Induction regimen & $\begin{array}{l}\text { "XA" } \\
\text { HAG }\end{array}$ & $\begin{array}{l}\text { IDA } \\
\text { Clofarabine } \pm \text { AraC }\end{array}$ & NA & LD-AraC \\
\hline CR rate, $\%$ & 62.8 & 53.7 & NA & 65 \\
\hline Overall survival & 9 months & 38 weeks & NA & NA \\
\hline Event/disease-free Survival & 8 months & 13 weeks & NA & NA \\
\hline
\end{tabular}

hAML, Hypocellular acute myeloid leukemia; AHD, anterior hematological disease; CR, complete remission

0.062). On multivariate analysis, poor cytogenetics and induction with XA regimen were independent predictive factors for induction failure (Table 5).

\section{Clinical outcomes}

The median follow up time was 12 months. For patients with $\mathrm{CR}$, the median OS in the HAG and XA groups was 16 months and 7 months, respectively $(P=$ 0.02 , Table 3, Figure 3A), while the median DFS was 16 months and 6.5 months, respectively $(P=0.23$, Table 3 , Figure 3B).

Six patients younger than 60-year old underwent allogeneic stem cell transplantation on achieving the first
$\mathrm{CR}$, and additional 3 patients underwent transplantation during CR2. Of the 9 patients who underwent allogeneic transplantation, 4 patients belonged to the HAG group, of whom 3 patients remain alive; 5 patients belonged to the XA group, of whom 3 patients remain alive at the time of writing this report. Most CR patients (24/27) recovered to normal hematopoiesis; among the patients who relapsed, hypocellular hematopoiesis recurred in 12 patients, while 3 patients developed hypercellular AML.

The CR rate for hypocellular and non-hypocellular AML was $62.8 \%$ and $56.0 \%$, respectively $(P=0.48)$. Twenty-seven $(62.8 \%)$ patients with hypocellular AML were treated with $\mathrm{XA}$ regimen and their $\mathrm{CR}$ rate was $51.9 \%$, with a median OS and DFS of 7 months and 6.5 months, respectively. Sixteen (37.2\%) patients were 

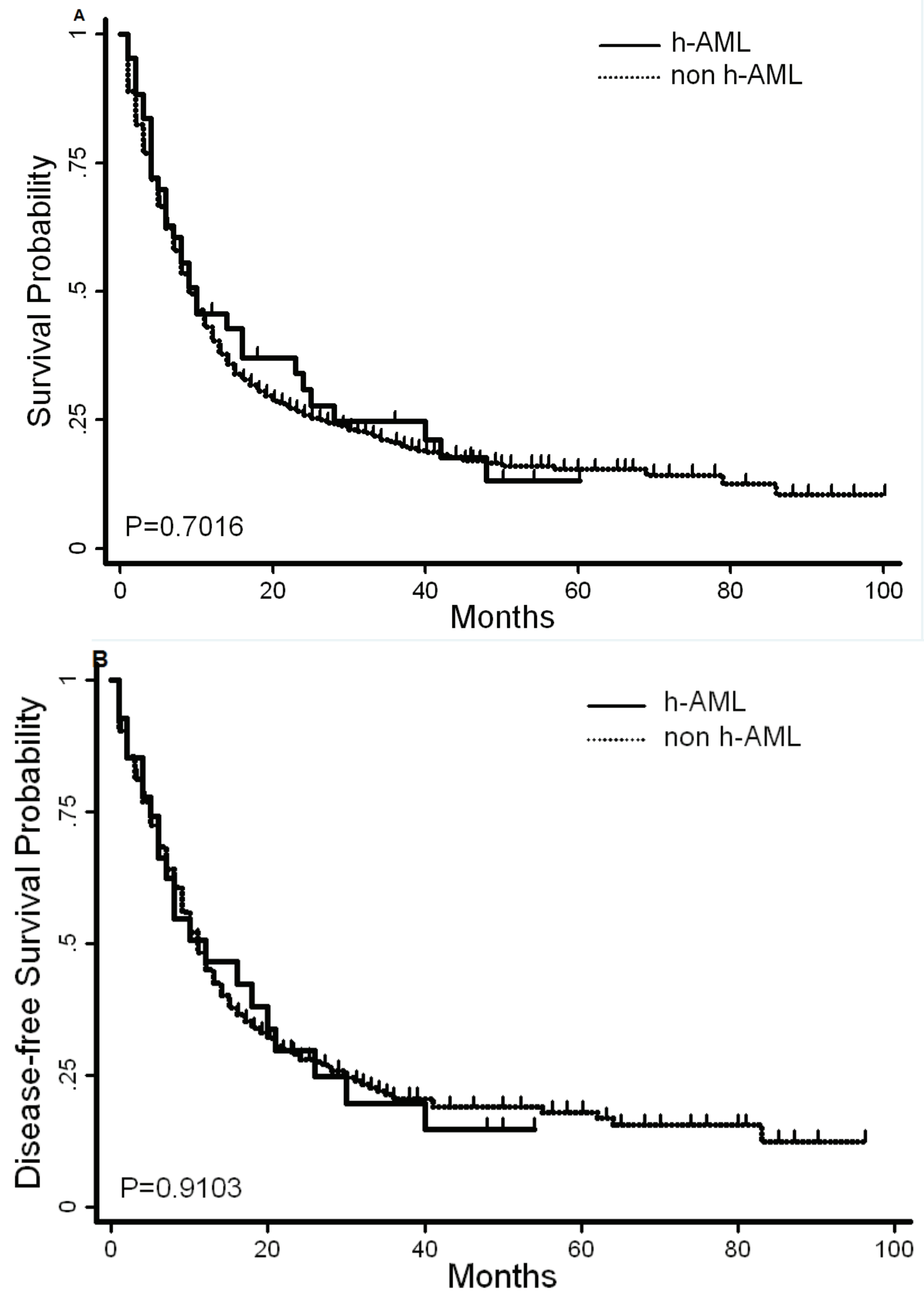

Figure 2: Overall survival and disease-free survival of AML patients with or without hypocellular feature. The median survival time in patients with hypo-AML and non-hypo AML was 9 and 8 months, respectively A., $P=0.7$. The median disease-free survival was 8 and 10 months, respectively B., $P=0.9$. 
treated with HAG and the CR rate in this cohort was $81.25 \%$ with a median OS and DFS of 16 months each. (Statistically better than the cohort treated with XA, Figure 2).

\section{Toxicity Profile of HAG regimen}

During remission induction, 5 out of 27 patients $(18.5 \%)$ in the XA group, and 6 out of $16(37.5 \%)$ patients in the HAG group developed reversible grade I-II liver dysfunction. $(P=0.365)$. Normal hepatic function was restored in all of these patients after termination of induction therapy. Abnormal electrocardiogram (ECG.) findings were observed in 6 of 27 patients in the XA group, and 5 of 16 patients in the HAG group $(P=0.471)$. On further investigation, however, the ECG alteration was not deemed to be of any pathophysiological significance. In general, the results of laboratory study and examination were comparable between the two groups. (Table S1).

\section{DISCUSSION}

In this study, we examined the incidence of hypoAML and undertook a systematic analysis of the clinical and laboratory characteristics in AML patients. The incidence of hypo-AML in our study was $7.4 \%$ of all AML, which is similar to that in the previous report (Table 6). [9] However, it is remarkable that the frequency of hypoAML was also comparable to that reported earlier (5-7\%) using the criteria of bone marrow cellularity of $40-50 \%$ for labeling a case as that of hypo-AML. The frequency was expected to be lower than that computed using the criteria of $<20 \%$ bone marrow cellularity. The similar frequency calculated with different diagnostic criteria could possibly be attributable to the differences in the diagnostic criteria for AML itself. Earlier, the diagnostic criteria for AML required at least 30\% myeloblasts in the bone marrow, which would decrease the incidence of AML, as the patients with $20-30 \%$ myeloblasts would then be diagnosed as cases of MDS-RAEB-T. In our study, the patients with $20-30 \%$ myeloblasts in bone marrow were diagnosed as AML, which is probably responsible for the increased yield of hypo-AML patients.

The median age of subjects in our study (56 years) was lower than that in the MD Anderson's report (65 years). In our study, 10 patients had ADH (6 MDS and $4 \mathrm{MPN}$ ), which is different from the report from the MD Anderson group that considered a wider spectrum of disease including MDS, non-Hodgkin lymphoma (NHL), Hodgkin lymphoma (HL) and other non-hematopoietic neoplasms with a history of chemotherapy (Table 6). The difference in the disease spectrum might be due to lower number of patients with ADH in our study. Nonetheless, the other clinical characteristics of hypo-AML patients were similar to those reported earlier. The outcomes of
hypo-AML did not appear to differ from that of nonhypocellular AML. In our study, the OS and DFS were comparable between hypo-AML and non-hypocellular AML patients. (Figure 2)

A notable finding from our study was a higher CR in hypo-AML patients treated with HAG regimen, as compared to those treated with XA, and that the increased $\mathrm{CR}$ rate did translate into prolonged OS and DFS. (Figure 3) On univariate analysis of induction failure in our study, AHD and poor cytogenetics markedly correlated with induction failure. On multivariate analysis, induction treatment regimen was observed to be an independent adverse prognostic factor for induction success along with other factors such as cytogenetics. Retrospectively, induction with HAG regimen is expected to benefit the adult AML patients with hypocellular bone marrow conferring an increased likelihood of achieving CR. The early death rate during HAG induction $(6.25 \%, 1 / 16)$ was lower than that associated with XA induction (14.8\%, 4/27) and cytarabine based induction (14\%, 17/123) employed in MD Anderson's report.[9]

Consistent with results from earlier studies, HAG regimen is highly effective in refractory or relapsed AML patients, with the reported CR rates varying from $43 \%$ to 70\%.[11-13] Similarly, another study showed that fifty percent (18/36) refractory and/or relapsed AML patients achieved CR with a median CR duration of 7.2 months. [11] These studies suggest HAG regimen to be highly effective in the treatment of refractory or relapsed AML. In the present study, patients with older age, AHD, and poor performance status tended to receive HAG induction, but they still achieved better survival rates as compared to that in the XA group.

The combination of cytarabine and anthracycline remains the cornerstone of chemotherapy for AML patients, with an associated remission rate of $70-75 \%$ in patients with de novo disease. In our study, XA regimen induced $\mathrm{CR}$ in $51.9 \%$ of patients. In MD Anderson's report, high dose cytarabine based regimens were used for two-thirds of patients, and induced $54 \%$ of patients with $\mathrm{CR}$, while the early death rate was high at $14 \%$. These results suggest that intensive chemotherapy induction might not be suitable for hypo-AML. The HAG regimen did show the advantage in the therapy of hypo-AML. In HAG group, the CR rate was $81.25 \%$, with a prolonged OS and DFS. Less intensive regimens like HAG appear to be optimal in hypo-AML patients. The higher sensitivity of hypo-AMLs to low dose cytarabine or melphalan has been documented. With low-dose cytarabine regimen, a significantly higher $\mathrm{CR}$ rate $(65 \%)$ was achieved in hypo-AML than in RAEB/RAEB-t ( $0 \%)$ and overt AML in the elderly cases (27.3\%).[6] Low-dose melphalan (oral $2 \mathrm{mg} / \mathrm{d}$ ) has been reported as being highly effective in inducing complete remission in relatively high-risk patients such as, elderly patients with AML, AML with multilineage dysplasia and those with MDS.[14,15,16] 
The HAG regimen contains low-dose cytarabine and G-CSF, which may contribute to the higher CR rate observed in patients with hypo-AML. Others have also described effective induction of remission with G-CSF $[17,18]$, possibly by inducing differentiation of leukemic blasts in the hypo-AML.[19] G-CSF is known to induce the differentiation of leukemic cells into the monocytic lineage, which causes apoptosis of leukemic cells, both in vivo and in vitro.[20] G-CSF stimulates the leukemia initiating cells into cell cycle, induces more leukemia cells sensitive to cytarabine, and enhances normal hematopoiesis.[19] CAG regimen which is similar to HAG, comprises of cytarabine, aclarubicin and G-CSF, which has been widely used in China and Japan for treatment of AML and MDS. A meta-analysis showed a significantly higher $\mathrm{CR}$ rates associated with $\mathrm{CAG}$ as compared to those of non-CAG regimens (odds ratio 2.43). [21] These findings are consistent with our observations in the present study. The small sample size is one of the limitations of our study which precludes any definitive
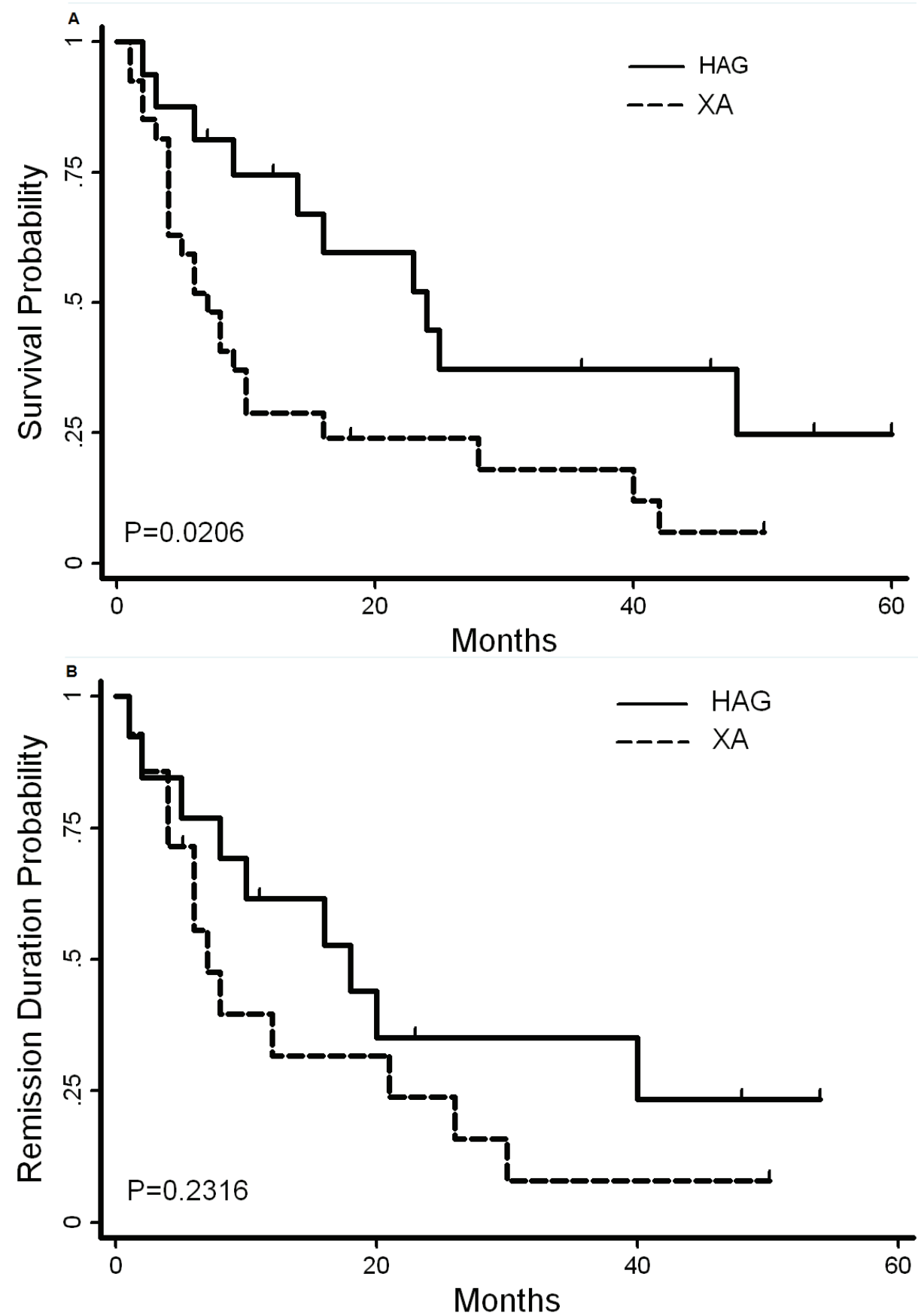

Figure 3: Overall survival and disease-free survival (DFS) of AML patients with hypocellular characteristics induced with XA or HAG. The median survival time for patients induced with XA and HAG was 7 and 16 months, respectively A., $P=0.02$. The median disease-free survival (DFS) was 6.5 and 16 months, respectively B., $P=0.2$ 
conclusions to be drawn. Our results just suggest that lower intensive regimen like HAG might be the optimal induction regimens for hypo-AML. Large, multi-center prospective studies are required to attain a comprehensive understanding of this disease entity.

In summary, the rare occurrence of hypo-AML is a challenge to its in proper diagnosis and rational treatment. In this study, use of HAG regimen as induction therapy was associated with superior outcomes and was an independent prognostic factor for OS.

\section{DESIGN AND METHODS}

\section{Patients' details}

Adult patients with newly diagnosed AML at the Department of Hematology, Changhai and Changzheng Hospital between January $1^{\text {st }}, 2003$ and December $31^{\text {st }}$, 2013 were retrospectively analyzed, excluding acute promyelocytic leukemia (APL) during the same period. The study protocol was approved by the Ethics Committee at the Second Military Medical University. Written informed consent was obtained from all patients (or their legal guardians) for treatment and prospective data collection in accordance with the Declaration of Helsinki. AML diagnosis was typed and characterized according to the WHO and FAB classification schemes. [22, 23]

\section{Bone marrow aspirate and pathology}

According to the clinical practice at our institute, bone marrow aspirate smears with core biopsies were performed on every patient at the time of presentation. Bone marrow aspirate smears were assessed by WrightGiemsa stain followed by their cytochemical analysis.

All cases with hypo-AML were reviewed by an independent pathologist including examination of peripheral blood smears, bone marrow aspirate smear and the bone marrow biopsies. The diagnosis criteria for hypo-AML adopted by the French-American-British Cooperative Leukemia Working Group in 2009 were used. [5] A bone marrow or blood blast count $\geq 20 \%$ in ANCs is required for a diagnosis of AML. If erythroid precursors in bone marrow account for $\geq 50 \%$ of bone marrow ANCs, then myeloblast count of $\geq 20 \%$ in non-erythroid cell population is required. A concomitant finding of bone marrow biopsy cellularity of $<20 \%$ is obligatory.

\section{Immunophenotyping analysis}

Seven-color flow cytometry immunophenotypic analysis was performed on bone marrow aspirate specimens using a fluorescence-activated cell sorting
(FACS) FACSAria II, as described previously.

\section{Cytogenetics analysis}

Direct and short-term culture methods were used for preparation of bone marrow specimens. Chromosome banding was carried out by heating using the R-banding method, with an average of 20 metaphase cells analyzed in each case. Karyotype was determined according to the International System for Human Cytogenetic Nomenclature (ISCN, 1995). Cytogenetic data was stratified into three subgroups (modified from previous complex karyotype [24-26]): Poor-risk (-5,-7, +8 and 11q involvement and complex karyotype), good-risk ( $\mathrm{t}(8 ; 21)$ or Inv $(16)$ or $t(16 ; 16))$ and intermediate-risk (neither good nor poor).

\section{Mutational analysis}

Bone marrow was the source of DNA in all cases. We sequenced the entire coding regions of NPM1 and FLT3-ITD. Paired remission DNA (i.e., DNA from patients who had a complete remission after induction chemotherapy) was available from 37 of the 43 participants. Data on variants that could not be validated as bona fide somatic mutations due to unavailable remission DNA and the absence of reports, the mutations in the published literature of somatic mutational status for that specific gene was used.

\section{Treatment}

Two kinds of induction chemotherapy regimen were used in our protocol for Hypo-AML. One was the standard regimen ("XA" regimen), which is comprised of daunomycin $45 \sim 60 \mathrm{mg} / \mathrm{m}^{2} / \mathrm{d} \mathrm{1-3}$ or idarubicin $8 \sim 10$ $\mathrm{mg} / \mathrm{m}^{2} / \mathrm{d} 1-3$, or mitoxantrone $8 \mathrm{mg} / \mathrm{m}^{2} / \mathrm{d} 1-3$ plus with cytarabine $100 \sim 150 \mathrm{mg} / \mathrm{m}^{2} / \mathrm{d} 1-7$. The other was HAG regimen, which is comprised of homoharringtonine (HHT, $1 \mathrm{mg} /$ day, intravenously, on days 1-14); cytarabine $25 \mathrm{mg} /$ $\mathrm{m}^{2} / 24 \mathrm{~h}$ divided into twice, subcutaneously, on days 1-14, and G-CSF $5 \mu \mathrm{g} / \mathrm{kg} / \mathrm{d}$ from d0 until the neutrophil counts above $1.5 \times 10^{9} / \mathrm{L}$. In XA cohort, G-CSF was given to patients at 48 hours after the end of chemotherapy while the neutrocyte was lower than $1.5 \times 10^{9} / \mathrm{L}$. For patients with WBC counts above $30 \times 10^{9} / \mathrm{L}$, hydroxyurea was given to decrease the WBC counts to less than $10 \times 10^{9} / \mathrm{L}$ for initiating chemotherapy with HAG regimen. The G-CSF priming was discontinued when WBC counts reached above $30 \times 10^{9} / \mathrm{L}$. Up to two cycles of induction therapy were allowed if CR was not achieved. Patients who achieved PR with one cycle of induction were re-induced with the same regimen.

Patients with CR were consolidated with four cycles 
of intermediate-dose cytarabine (ID-Ara-C, $2 \mathrm{~g} / \mathrm{m}^{2}, \mathrm{q} 12 \mathrm{~h}$, for 6 doses). 9 patients received allogeneic hematopoietic stem cell transplantation with eligible matched related or unrelated donors after the attainment of CR. The conditioning regimen included busulfan $(3.2 \mathrm{mg} / \mathrm{kg} / \mathrm{d} \times 4$ days) and cyclophosphamide $(60 \mathrm{mg} / \mathrm{kg} / \mathrm{d} \times 2$ days $)$.

\section{Criteria for response and definition of disease-free survival}

CR was defined by the presence of $<5 \%$ blasts in the bone marrow, absence of extramedullary leukemia, and peripheral blood count recovery with a neutrophil count of at least $1 \times 10^{9} / \mathrm{L}$ and platelet count of at least $100 \times 10^{9} /$ L. $[27,28]$ PR was defined as $5-15 \%$ blasts with a decrease of at least $50 \%$ reduction of bone marrow blasts at diagnosis. Relapse was defined by an excess of 5\% leukemic blasts in a marrow aspirate unrelated to recovery of normal hematopoiesis, or the development of new extramedullary leukemia. DFS was calculated from the date of first CR. All patients were followed up from the time of their diagnosis until the end of December, 2014.

\section{Statistical methods}

Chi-squared tests and non-parametric MannWhitney tests were used for descriptive statistical analysis of categorical or continuous variables. The impact of pathological feature on OS and DFS was estimated using the Kaplan-Meier method and compared using log rank analysis.[29] For multivariate analysis, stepwise Cox proportional hazard (95\% confidence intervals [CI]) were performed using R 2.7.2 software package.

\section{ACKNOWLEDGMENTS}

This work was supported by National Natural Science Foundation of China (NSFC; 81090413, 81370601, 81070394, 81270567, 81470321). X.H. was sponsored by Young Scholarship from Shanghai Health Bureau (XYQ2011007).

\section{Authors' contributions}

Contribution: X.H. designed the study, collected and verified patient information, analyzed and interpreted data, and wrote the manuscript; W.F. collected clinical and immunophenotypic data, interpreted data, and wrote the manuscript; analyzed data, performed statistical analysis and verified patient information; L.W., L.G., S.L., H.X., H.Q., L.C., J.C., X.N., X.Q., W.Z., J.Y., and J.W. recruited the patients, performed diagnosis and treatment; and X.S. is the principal investigator, designed research, interpreted data, and critically reviewed the manuscript.

\section{CONFLICTS OF INTEREST}

The authors declare no competing interests.

\section{REFERENCES}

1. Tuzuner N, Cox C, Rowe JM and Bennett JM. Hypocellular acute myeloid leukemia: the Rochester (New York) experience. Hematologic pathology. 1995; 9:195-203.

2. Needleman SW, Burns CP, Dick FR and Armitage JO. Hypoplastic acute leukemia. Cancer. 1981; 48:1410-1414.

3. Beard ME, Bateman CJ, Crowther DC, Wrigley PF, Whitehouse JM, Fairley GH and Scott RB. Hypoplastic acute myelogenous leukaemia. British journal of haematology. 1975; 31:167-176.

4. Berdeaux DH, Glasser L, Serokmann R, Moon T and Durie BG. Hypoplastic acute leukemia: review of 70 cases with multivariate regression analysis. Hematol Oncol. 1986; 4:291-305

5. Bennett JM and Orazi A. Diagnostic criteria to distinguish hypocellular acute myeloid leukemia from hypocellular myelodysplastic syndromes and aplastic anemia: recommendations for a standardized approach. Haematologica. 2009; 94:264-268.

6. Nagai K, Kohno T, Chen YX, Tsushima H, Mori H, Nakamura H, Jinnai I, Matsuo T, Kuriyama K, Tomonaga $\mathrm{M}$ and Bennett JM. Diagnostic criteria for hypocellular acute leukemia: a clinical entity distinct from overt acute leukemia and myelodysplastic syndrome. Leukemia research. 1996; 20:563-574.

7. Tomonaga M. [Hypocellular acute leukemia]. Rinsho Ketsueki. 1995; 36:457-464.

8. Swerdlow SH, Campo, E., Harries, N.L., Jaffe, E.S., Pileri, S.A., Stein, H., Thiele, J., Vardiman, J.W. WHO Classification of Tumors of Haematopoietic and Lymphoid Tissues. Lyon, France: IARC. 2008.

9. Al-Kali A, Konoplev S, Lin E, Kadia T, Faderl S, Ravandi F, Ayoubi M, Brandt M, Cortes JE, Kantarjian H and Borthakur G. Hypocellular acute myeloid leukemia in adults: analysis of the clinical outcome of 123 patients. Haematologica. 2012; 97:235-240.

10. Shano Naseem TS, Narender Kumar, Neelam Varma, Reena Das, Jasmina Ahluwalia, MUS Sachdeva, Prashant Sharma, Pankaj Malhotra, Subhash Varma. Hypocellular acute leukemia: study of clinical and hematological features. J Hematopathol. 2014; 7:147-152.

11. Zhang WG, Wang FX, Chen YX, Cao XM, He AL, Liu J, Ma XR, Zhao WH, Liu SH and Wang JL. Combination chemotherapy with low-dose cytarabine, homoharringtonine, and granulocyte colony-stimulating factor priming in patients with relapsed or refractory acute myeloid leukemia. American journal of hematology. 2008; 83:185-188.

12. Gu LF, Zhang WG, Wang FX, Cao XM, Chen YX, He AL, 
Liu J and Ma XR. Low dose of homoharringtonine and cytarabine combined with granulocyte colony-stimulating factor priming on the outcome of relapsed or refractory acute myeloid leukemia. Journal of cancer research and clinical oncology. 2011; 137:997-1003.

13. Lu S and Wang J. Homoharringtonine and omacetaxine for myeloid hematological malignancies. Journal of hematology \& oncology. 2014; 7:2.

14. Omoto E, Deguchi S, Takaba S, Kojima K, Yano T, Katayama Y, Sunami K, Takeuchi M, Kimura F, Harada M and Kimura I. Low-dose melphalan for treatment of highrisk myelodysplastic syndromes. Leukemia. 1996; 10:609614.

15. Robak T, Szmigielska-Kaplon A, Urbanska-Rys H, Chojnowski K and Wrzesien-Kus A. Efficacy and toxicity of low-dose melphalan in myelodysplastic syndromes and acute myeloid leukemia with multilineage dysplasia. Neoplasma. 2003; 50:172-175.

16. Denzlinger C, Bowen D, Benz D, Gelly K, Brugger W and Kanz L. Low-dose melphalan induces favourable responses in elderly patients with high-risk myelodysplastic syndromes or secondary acute myeloid leukaemia. British journal of haematology. 2000; 108:93-95.

17. Takamatsu Y, Miyamoto T, Iwasaki H, Makino S and Tamura K. Remission induction by granulocyte colonystimulating factor in hypoplastic acute myelogenous leukemia complicated by infection. A case report and review of the literature. Acta haematologica. 1998; 99:224230 .

18. Lee M, Chubachi A, Niitsu H, Miura I, Yanagisawa M, Hirokawa M and Miura AB. Successful hematopoietic reconstitution with granulocyte colony-stimulating factor in a patient with hypoplastic acute myelogenous leukemia. Internal medicine. 1995; 34:692-694.

19. Nimubona S, Grulois I, Bernard M, Drenou B, Godard M, Fauchet R and Lamy T. Complete remission in hypoplastic acute myeloid leukemia induced by G-CSF without chemotherapy: report on three cases. Leukemia. 2002; 16:1871-1873.

20. de Bock R, de Jonge M, Korthout M, Wouters E, van Bockstaele D, van der Planken $\mathrm{M}$ and Peetermans $\mathrm{M}$. Hypoplastic acute leukemia: description of eight cases and search for hematopoietic inhibiting activity. Annals of hematology. 1992; 65:247-252.

21. Wei G, Ni W, Chiao JW, Cai Z, Huang H and Liu D. A meta-analysis of CAG (cytarabine, aclarubicin, G-CSF) regimen for the treatment of 1029 patients with acute myeloid leukemia and myelodysplastic syndrome. Journal of hematology \& oncology. 2011; 4:46.

22. Vardiman JW, Thiele J, Arber DA, Brunning RD, Borowitz MJ, Porwit A, Harris NL, Le Beau MM, Hellstrom-Lindberg E, Tefferi A and Bloomfield CD. The 2008 revision of the World Health Organization (WHO) classification of myeloid neoplasms and acute leukemia: rationale and important changes. Blood. 2009; 114:937-951.
23. Bennett JM, Catovsky D, Daniel MT, Flandrin G, Galton DA, Gralnick HR and Sultan C. Proposed revised criteria for the classification of acute myeloid leukemia. A report of the French-American-British Cooperative Group. Ann Intern Med. 1985; 103:620-625.

24. Grimwade D, Walker H, Oliver F, Wheatley K, Harrison C, Harrison G, Rees J, Hann I, Stevens R, Burnett A and Goldstone A. The importance of diagnostic cytogenetics on outcome in AML: analysis of 1,612 patients entered into the MRC AML 10 trial. The Medical Research Council Adult and Children's Leukaemia Working Parties. Blood. 1998; 92:2322-2333.

25. Slovak ML, Kopecky KJ, Cassileth PA, Harrington DH, Theil KS, Mohamed A, Paietta E, Willman CL, Head DR, Rowe JM, Forman SJ and Appelbaum FR. Karyotypic analysis predicts outcome of preremission and postremission therapy in adult acute myeloid leukemia: a Southwest Oncology Group/Eastern Cooperative Oncology Group Study. Blood. 2000; 96:4075-4083.

26. Byrd JC, Mrozek K, Dodge RK, Carroll AJ, Edwards CG, Arthur DC, Pettenati MJ, Patil SR, Rao KW, Watson MS, Koduru PR, Moore JO, Stone RM, Mayer RJ, Feldman EJ, Davey FR, et al. Pretreatment cytogenetic abnormalities are predictive of induction success, cumulative incidence of relapse, and overall survival in adult patients with de novo acute myeloid leukemia: results from Cancer and Leukemia Group B (CALGB 8461). Blood. 2002; 100:4325-4336.

27. Estey EH, Thall PF, Wang X, Verstovsek S, Cortes J and Kantarjian HM. Effect of circulating blasts at time of complete remission on subsequent relapse-free survival time in newly diagnosed AML. Blood. 2003; 102:30973099.

28. Cheson BD, Cassileth PA, Head DR, Schiffer CA, Bennett JM, Bloomfield CD, Brunning R, Gale RP, Grever MR, Keating MJ and et al. Report of the National Cancer Institute-sponsored workshop on definitions of diagnosis and response in acute myeloid leukemia. J Clin Oncol. 1990; 8:813-819.

29. Kaplan EL. The group A beta hemolytic streptococcus. No longer just a nuisance? Minnesota medicine. 1994; 77:2527. 